\title{
DEFECT ASSESSMENT BASED ON GROSS SECTION YIELDING IN WIDE PLATE TESTS
}

\section{R. M. Denys}

Gent University, St. Pietersnieuwstraat 41, B - 9000 GENT, Belgium

\section{ABSTRACT}

A brief outline is given of the applicability of wide plate testing for the ssessment of the significance of defects on failure behaviour for notch ductile materials. Wide plate test results are assessed using the Gross section Yielding concept. This concept aims to define a maximum tolersblo defect size a for gross section yielding before fracture ensues. The axamples given illustrate that this approach permits a realistic assessment of the integrity of structures serving an important safety function.

\section{KEYWORDS}

Precture mechanics, wide plate testing and gross section yielding.

\section{INTRODUCTION}

In assessing how welds and weld defects might affect fitness for purpose, it is seen from literature that one relies either on test results obtained from mall test specimens (such as Charpy- $v$ specimens) and/or intermediate scale tests (such as the CTOD tests). However, these approaches, which are to be considered as a final goal, may. pose serious problems. The range of problems to which the existing methods are applied, can be divided into two categories.

The first category includes these cases where the final decision depends upon the required impact properties. Most people feel uneasy about applying the criteria established for C and C-Mn steels (upon which most codes are based to modern materials. Indeed, it is common practice that most requirements testing 
The second category includes these cases where the application of single notch tip fracture toughness parameters such as CTOD, J.. is recomended. Again, the engineer feels unhappy about a generalisation of the defect tolerance calculation methods, which are - mainly for analytical reasons -, always the result of simplifications of the real problem. In approach may be extrapolated considering a coherent besis work was based on.

As a consequence the author believes that for modern and tough materials the engineering significance of defects with regard to fracture initiation and propagation may not always be quantified by fracture mechanics methods diretly without making reference to full scale behaviour. Especially for high performance and expensive structures a widespread adoption of fitness detailed knowledoaches based on fracture mechanics requires a more predictions and uneconomical soty factors. Only then unnecessarily cautious predictions and uneconomical solutions can be avoided. Therefore, we are thelined to advocate the need for tests e.g. Wide plate tests, resemblin the actual structural detail and which are subjected to conditions that

might be regarded as similar to those encountered in service.

Although the wide plate test does not correlate exactly with service experience, it answers at least a lot of puzzling questions with regard to the fitness for purpose philosophy. Following this line of thought, it is almost self-evident that once we are prepared to utilize the actual material properties (which differ from the idealized perfectly elastic-plastic characteristics) in ductile strain hardening materials the indeed numerous - Denys (1). Moreover, the author ritness for purpose are recommendation for wide plate testing applies only for in that the expensive structures.

The assessment of wide plate test results to prevent the occurrence of unexpected and sudden failures in engineering structures and components has been the subject of intensive research at the Gent University. Based upon the progress which has been achieved and the knowledge of the many factors influencing a reliable and non conservative assessment of defects an overall assessment concept has been developed. By applying the concept elastic-plaction Yielding" (GSY) to situations in which the elastic-plastic fracture mechanics is either invalidated or over plastic collapse behaviour) yielding (i.e. yielding beyond the so called approa collapse behaviour), it will be shown hereinafter that this principles in a more practical to examine and apply fitness for purpose

\section{ASSESSMENT OF WIDE PLATE TEST RESULTS}

The wide plate test results are normally used to confirm the validity of refect tolerance calculations from small scale data. For this purpose, reference is frequently made to the most widely applied method in the elastic plastic regime: the CTOD design curve. However, serious problems arise when the wide plate test exhibits fully ductile behaviour. In these cases it is suggested to assess failure prediction by plastic collapse.

The adopted methods for dealing with plastic collapse are ill-defined with

respect to tolerable defect size estimations. To overcome the limitations
It is proposed to judge the wide plate behaviour in quite a different manner.

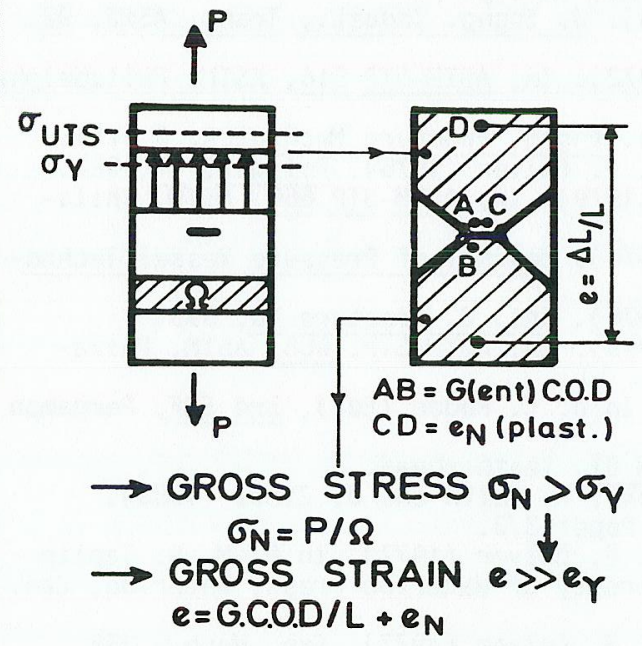

It is evidently much more realistic to look for criteria which relate to practical behaviour and which are easy to use. In the author's opinion, the estimation of safety, the significance of defects, and thus service performance, and be directly related to the overall behaviour. The assessment of overall behaviour can only be based on either gross strength or gross ductility. For convenience, it is preferable to look for strength, and if we claim gross strength of at least yield point magnitude we automatically obtain a good overall ductility. The philosophy behind this requirement is explained in Figure 1, and is based on extensive experimental work carried out at the Gent University. The method for assessing wide plate test results is referred to as the "Gross Section Yielding" approach .

GROSS SECTION YIELDING CONCEPT

The origin of the Gross Section Yielding approach is based on the employment of full thickness wide plate specimens containing a notch. The notch is located in that area of plate where high deformations will occur and in these regions where low toughness values are to be expected. The notched wide plate specimen is subsequently subjected to a tensile load at the minimum operating temperature. The use of full thickness ensures further that the constraint in the specimen matches that in the structure.

The experience in using this testing method for various kinds of materials and defect geometries (through thickness-, surface and buried defects), revealed that three distinct deformation modes can occur. The 'net section stress at fracture either exceeds the material's uniaxial yield stress $10.2 \%$ proof stress) and the flawed wide plate specimen deforms by NET or GROSS section yielding. Or the net section stress at fracture is below the uniaxial yield stress, so that only CONTAINED yielding occurs - see Figur 2. The analysis of these deformation modes in relation with decreasing crack dimensions indicates that tough materials deform either by GSY or by NSY, whilst for less tough materials the sequence of deformation modes to be considered are GSY, NSY, CY and NSY. This difference may be explained by the plate width effects (1) Apart from the apparent plate width effect, it is obvious that for both situations a shift from GSY to NSY exists. 


\section{$\sigma_{\mathrm{N}}<\sigma_{\mathrm{n}}<\sigma_{\mathrm{Y}}$

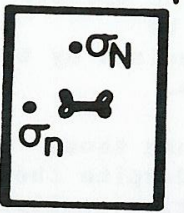 \\ CONTAINED \\ YIELDING}
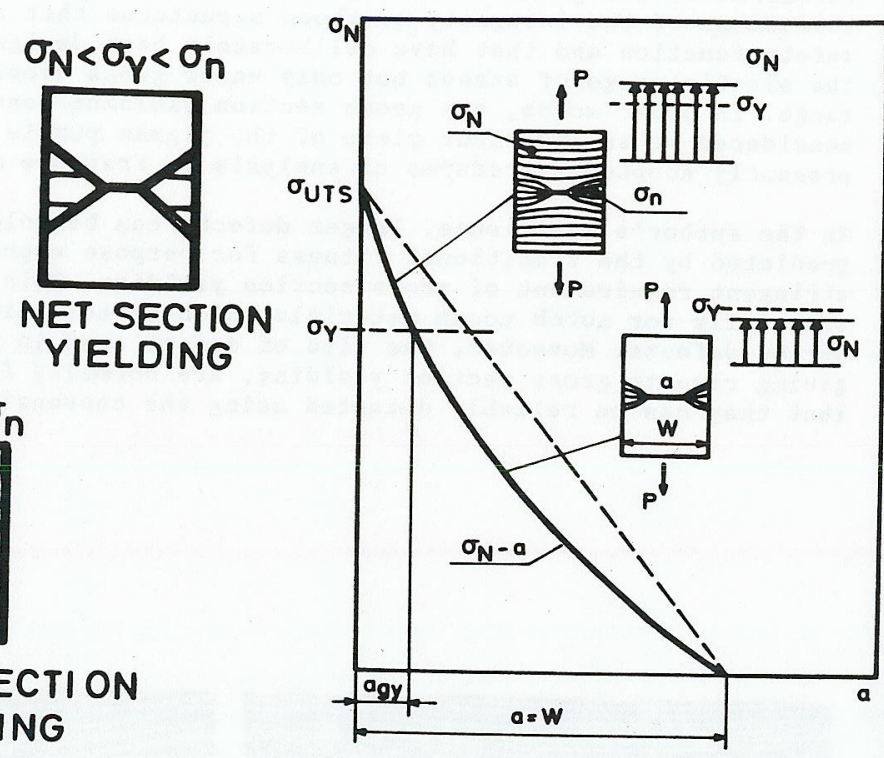

Fig. 3 Gross stress dependence
of crack length.

Fig. 3 Gross stress dependence
of crack length. section yielding.
Fig. 2 CONTAINED, NET and GROSS
These observations led to the consideration of a direct approach of defect tolerance, solely based upon wide plate testing. The demarcation between NET to GROSS section yielding permits estimation of the maximum tolerable smaller than gross section yielding agy. (Fig.3). Thus, a defect overall elongation induces gross section yielding guaranteeing a good Consequently it can be construed of at least yield point magnitude. acceptable. At this stage, we must emphasize that we utilize and asses the actual material properties for safety assessments in notch tough strain hardening materials, and that we do NOT allow gross yielding in the structure.

We only utilize the deformation phenomenon observed in wide plate test specimens to define acceptable defect sizes Moreover, the possibility of gross section yielding may be considered as a
safeguard in case of e.g. accidental overloading.

\section{METHOD OF APPLICATION}

Since the purpose of this paper is not to acquaint the reader with all the experimental details of wide plate testing, only the general outlines will be described hereinafter. To apply the GSY concept the following
experimental data are required: 1. The uniaxial yield strength of the (parent) material at the minimum
operating temperature.
2. The ultimate tensile strength of the defective region (i.e. from the material containing the defect - only necessary for the determination of agy - see also further)

3. The gross stress at fracture (i.e. the load at fracture/gross section) of the wide plate specimen.

The maximum tolerable defect size $a_{g y}$ is that at which the gross section failure stress equals the yield stress of the plate (Fig. 3).

The method has also been developed to incorporate consideration of transverse weldments and to cover through thickness surface and buried defects - Denys $(2,3)$. It should be noted that for the cases of transverse welds, in which both HAZ and weld metal overmatch the parent plate in yield stress, it is in principle only necessary to exceed the yield stress of the parent material to achieve gross section yielding.

It should be emphasized that the gross section yielding concept is not always applied to define the maximum tolerable defect size a . It is rather intended to check whether a particular defect can be safely left in a structure.

For instance, in case the notch toughness (code) requirements (such as $C_{v}$ or/and CTOD) are not achieved and as soon as the material used has strain hardening properties, it can be justified to apply the GSY concept. In these circumstances, it is considered that a defect can be present, even when NDT reveals no defects, so that the evaluation will be recategorized in a fitness for purpose approach. For this purpose, large scale or wide plate test with a defect of detectable size will be carried out in order to check wether gross section yiolding can bo obtalned. If that is the case, it is the experience that a code relaxation can be discussed with the governmental quality control authoritias.

Finally, the GSY concept, as it stands, is currently applied to asasa defects in structural elements such as pipes, storage tanks, plate and nozzle intersections, etc ...

\section{PRACTICAL APPLICATION}

The following example illustrate the application of the method just described.

Check whether buried defect of $10 \mathrm{~mm} \times 50 \mathrm{~mm}$ and a continuous embedded defect $10 \mathrm{~mm} \times 350 \mathrm{~mm}$ located in the $\mathrm{HAZ}$ of $30 \mathrm{~mm}$ thick welded StE 355 plates are acceptable $\left(t=-20^{\circ} \mathrm{C}\right)$. The following general data are available - Denys, Musgen (4).

The submerged arc welding procedure, with $K$ preparation, was used (as it was envisaged to sample the HAZ only). The heat input was $2,5 \mathrm{~kJ} / \mathrm{m}$. PWHT was applied.

The weld metal yield strength approximately matches that of the plate. The mechanical properties at $-20^{\circ} \mathrm{C}$ as determined on wide plate specimens of plain material gave a yield strength of $425 \mathrm{~N} / \mathrm{mm}^{2}$ and a $\sigma_{u}$ of 629 $\mathrm{N} / \mathrm{mm}^{2}$. The minimum CTOD values at $-20^{\circ} \mathrm{C}$ (specimen size $2 \mathrm{BxB}$ ) for $\mathrm{HAZ}$ and plate material were $0.23 \mathrm{~mm}$ and $0.96 \mathrm{~mm}$ respectively. 


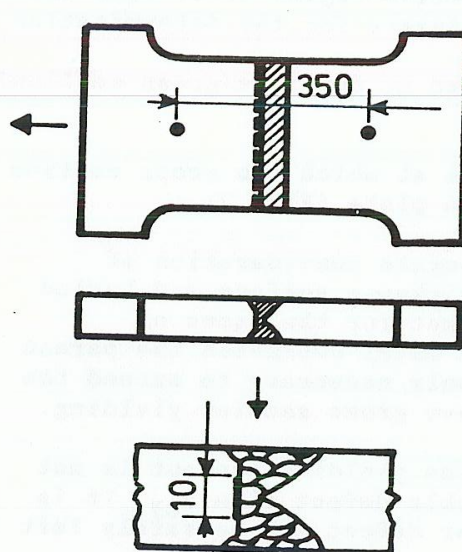

BURIED DEFECT

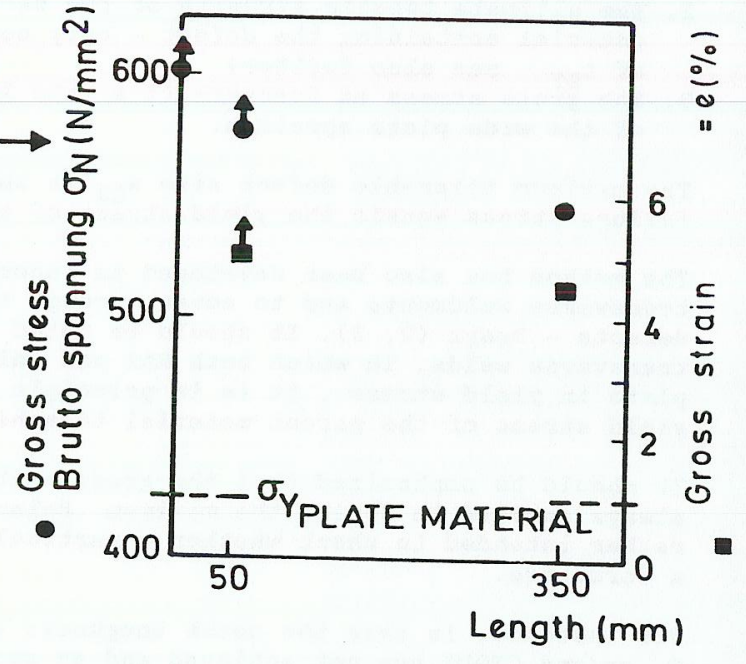

Fig. 4 Measured gross stress and gross strain of weldment with an embedded defect.

The test results, depicted in Figure 4, show that gross section yieldin occurred irrespective of defect dimensions. It is remarkable to see that a buried defect with a section equalling one third of the plate section failed at $5 \%$ gross strain. In order to assist in evaluating the

deformation mode, a selection of moiré pictures is given in Figures $5 \mathrm{a}$ and b. The interference patterns confirms that gross section yigures ccurred. The moiré fringes in the unnotched

clearly visible. From the high density of moin

$5 \mathrm{a}$, the buried defect of

FINAL OBSERVATIONS - CONCLUSIONS

An outline has been given of the applicability of wide plate testing for wide concept. concept. This for gross section yielding before fracture ensues. These maximum tolerable dimensions enables the definition of acceptable defects. Defects smaller than ay are considered to be acceptable, since they tolerate a strength of at least yield point magnitude and a sufficient overall ductility.

The gross section yielding concept must be considered as a direct fitness for purpose approach. This concept, which gives an adequate margin of safety in terms of overall deformation, should be considered as either an alternative, or a complementary method that should be used together with defect tolerance calculation methods based on a single crack tip fracture toughness parameter. Wide plate testing is in particular recommended for expensive structures for which conservative defect tolerance levels may prove to be extremely expensive.
Furthermore, the gross section yielding concept permits a realistic assessment of the integrity of those structures that serve an important afety function and that have deliberately been designed not to fail in the elastic range of stress but only under gross overload in the plastic range. In other words, the gross section yielding concept can be considered as an important piece of the jigsaw puzzle characterized by the presently adopted procedures of analysis in fracture mechanics.

In the author's experience, larger defects can be tolerated than those predicted by the traditional fitness for purpose approaches, despite the atringent requirement of gross section yielding. This observation applies - specially for notch tough materials which contain either surface or buried defects. Moreover, the size of defect used in wide plate testing giving rize to gross section yielding, are normally found to be so large that they can be reliably detected using the convensional NDT techniques.
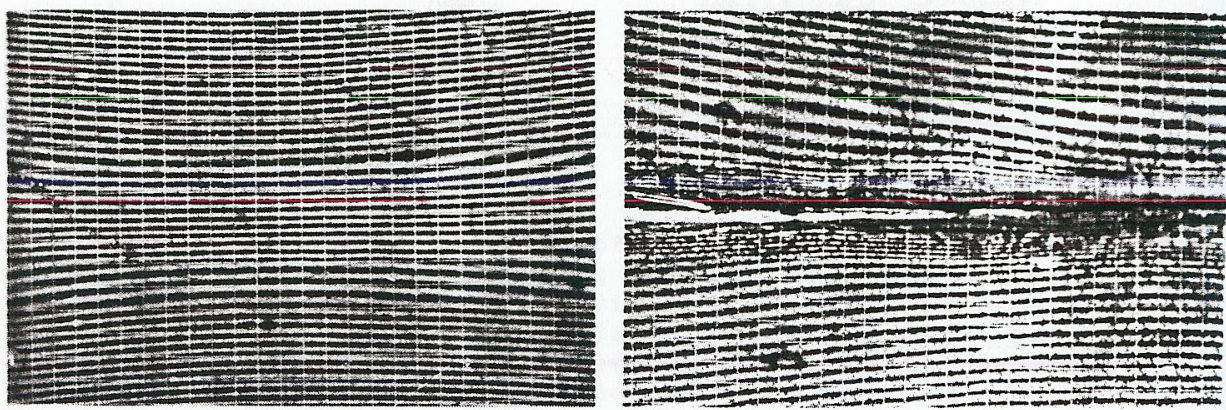

Fig. 5 Moiré pictures of weldments with a buried defect. $\begin{array}{ll}\text { a) } 10 \mathrm{~mm} \times 50 \mathrm{~mm} & \text { b) } 10 \mathrm{~mm} \times 350 \mathrm{~mm}\end{array}$

SYMBOLS USED

By =Value of a, demarcating Gross section/Net section yielding.

GCOD =Gent Crack Opening Displacement (Gauge length : $8 \mathrm{~mm}$ ).

GSY. =Gross section yield (i.e. gross stress > yield stress)

NSY. =Net section yield (i.e. gross stress < yield stress). 


\section{ACKNOWLEDGEMENTS}

The author wishes to express his gratitude to I.W.O.N.L. - Brussels Belgium for the financial support to perform this investigations.

\section{REFERENCES}

DENYS, R., 1983, Absicherung des weitersbetreibs fehlerbehaf teter Bauteile durch Grossplattenversuchen, TUV Conference proceedings - Mit Rissen DENYS R 1982 , W.Germany

defects, WI Congress proceedings and its application to acceptable

defects, WI Congress Proceedings Fracture Toughness Testing -

DENYS, R., 1979, Plastische breukmechanica - Heter - Paper 13-London. materiaal- PT werktuigbouw $34-1$ en 2 Den Hage. 1

DEN $\backslash$, , R., and MUESGEN, B, 1982, Gross section yielding crack tolerance St E 355 and St E 690 steels - WI Congress

Proceedings Fracture Toughness Testing - Methods,

Interpretation and application -June - Paper 12 - London 